\title{
Características da rede social de apoio ineficaz: revisão integrativa
}

\author{
Characteristics of the ineffective social support network: integrative review \\ Características de la red social de apoyo ineficaz: revisión integrativa
}

\author{
Michelline Santos de França ${ }^{a}$ \\ Marcos Venícios de Oliveira Lopes ${ }^{b}$ \\ Cecília Maria Farias de Queiroz Frazão ${ }^{a}$ \\ Tatiane Gomes Guedes ${ }^{a}$ \\ Francisca Márcia Pereira Linhares ${ }^{a}$ \\ Cleide Maria Pontes ${ }^{a}$
}

\section{Como citar este artigo:}

França MS, Lopes MVO, Frazão CMFQ

Guedes TG, Linhares FMP, Pontes

CM. Características da rede social de apoio ineficaz: revisão integrativa. Rev Gaúcha Enferm. 2018;39:e20170303. doi: https://doi.org/10.1590/19831447.2018.20170303. aniversidade Federal de Pernambuco (UFPE), Centro de Ciências da Saúde, Programa de Pós-Graduação em Enfermagem. Recife, Pernambuco, Brasil.

' Universidade Federal do Ceará (UFC), Faculdade de Farmácia, Odontologia e Enfermagem, Programa de Pós-Graduação em Enfermagem. Fortaleza, Ceará, Brasil.

\section{RESUMO}

Objetivo: Avaliar as características da rede social de apoio ineficaz evidenciadas em sua estrutura, funcionalidade e dinâmica. Método: Revisão integrativa, realizada em dezembro de 2017, nas bases Scopus, CINAHL, Web of Science, CUIDEN, BDENF, Lilacs e biblioteca SciELO por meio de combinações entre descritores - Rede Social, Redes Sociais, Apoio Social, Redes de Apoio Social e 0 termo "ineficaz" - encontrando-se 2.012 publicações e 24 compuseram a amostra. A análise dos resultados foi alicerçada nas dimensões da Rede Social de apoio.

Resultados: Na dimensão estrutural, observaram-se características referentes à amplitude, densidade da rede e fragilidade dos laços; na funcional, o não cumprimento da função de apoio social em diferentes ocasiões; na dinâmica, conflitos e situações inesperadas interferiram negativamente.

Conclusão: A avaliação das características de rede social de apoio ineficaz permite melhor compreensão das relações e instrumentaliza enfermeiros na mobilização dessas redes direcionada ao bem-estar da pessoa, família e coletividade.

Palavras-chave: Rede social. Apoio social. Enfermagem. Diagnóstico de enfermagem. Processo de enfermagem. Educação em saúde.

\section{ABSTRACT}

Objective: To evaluate the characteristics of the ineffective social support network evidenced in its structure, functionality and dynamics. Method: Integrative review, carried out in December 2017, in the bases Scopus, CINAHL, Web of Science, CUIDEN, BDENF, Lilacs and SciELO library by means of combinations between keywords/descriptors - Social Network, Social Networks, Social Support, Social Support Networks and the term "ineffective", finding 2012 publications and 24 composed the sample. The analysis of the results was based on the dimensions of the Social Support Network.

Results: In the structural dimension, it was observed characteristics related to the amplitude, density of the network and fragility of the bonds; in the functional, the non-fulfillment of the function of social support in different occasions; and in the dynamics, conflicts and unexpected situations interfered negatively.

Conclusion: The evaluation of the characteristics of the ineffective social support network allows a better understanding of their relationships and instrumentalizes nurses in the mobilization of these networks directed to the well-being of the person, family and community. Keywords: Social networking. Social support. Nursing. Nursing diagnosis. Nursing process. Health education.

\section{RESUMEN}

Objetivo: Evaluar las características de la red social de apoyo ineficaz evidenciadas en su estructura, funcionalidad y dinámica. Método: Revisión integradora, realizada en diciembre de 2017, en las bases Scopus, CINAHL, Web of Science, CUIDEN, BDENF, Lilacs y biblioteca SciELO, por medio de combinaciones entre descriptores - Red Social, Redes Sociales, Apoyo Social, Redes de Apoyo Social y el término "ineficaz" -, encontrándose 2012 publicaciones y 24 compusieron la muestra. El análisis de los resultados se basó en las dimensiones de la Red Social de apoyo.

Resultados: En la dimensión estructural, se observaron características referentes a la amplitud, densidad de la red y fragilidad de los lazos. En la funcional, el no cumplimiento de la función de apoyo social en diferentes ocasiones fue evidenciado. En la dinámica, conflictos y situaciones inesperadas interfirieron negativamente.

Conclusión: La evaluación de las características de red social de apoyo ineficaz permite una mejor comprensión de sus relaciones e instrumentaliza a los enfermeros en la movilización de esas redes dirigidas al bienestar de la persona, familia y colectividad.

Palabras clave: Red social. Apoyo social. Enfermería. Diagnóstico de enfermería. Proceso de enfermería. Educación en salud. 


\section{—INTRODUÇÃO}

As redes sociais de uma pessoa correspondem aos contatos interpessoais, responsáveis por manter a sua identidade social. Também dão forma às relações sociais e são classificadas em redes primárias - representadas por laços de família, parentesco, amizade, vizinhança e trabalho - e em redes secundárias. Estas podem ser formais - constituídas por laços com instituições e organizações - e informais - estabelecidas pela ligação entre pessoas para responder a uma necessidade imediata ${ }^{(1)}$.

As redes sociais, primárias ou secundárias, apresentam três dimensões: estrutura, funções e dinâmica. A estrutura consiste no conjunto de laços que se estabelecem entre pessoas e entre redes, e o acionamento desses laços gera conexões que conferem o formato da rede. Nessa dimensão, observa-se o tamanho da rede, que se refere à quantidade de indivíduos que interagem entre si; a densidade da rede, determinante do grau em que as relações entre os atores sociais são interligadas; a composição da rede engloba a classificação do tipo de laços; e a homogeneidade representa a proporção de vínculos. As funções desempenhadas pela rede são intermediadas pela estrutura, e são definidas como suporte e contenção. A dinâmica das redes é realizada pelos movimentos de informações e forças internas, que convergem em pontos de maior carga e são redistribuídos ${ }^{(1-2)}$.

A rede social de apoio pode ser avaliada pelo enfermeiro a partir de um indivíduo focal e, por meio dele, identificar seus laços sociais - rede egocêntrica; ou um grupo de indivíduos e as relações existentes entre eles - rede completa $^{(3)}$. O enfermeiro e/ou o profissional da saúde pode distinguir as redes sociais das pessoas a quem presta cuidado de ambas as formas, no entanto, uma análise de rede egocêntrica pode permitir a compreensão mais ampla tanto da estrutura quanto da função de apoio dessas redes.

Esse apoio social é imprescindível no cuidado, uma vez que o ser humano necessita de relações interpessoais, integra uma rede social de apoio e a aciona para enfrentamento e resolução de situações diversas em sua vida ${ }^{(4)}$. Tal ajuda pode ser entendida em seu caráter de apoio recebido e apoio percebido. O recebido é aquele fornecido pela rede ao destinatário, já o percebido reflete a percepção do destinatário quanto à disponibilidade e satisfação com o apoio(5), e está mais intimamente relacionado aos resultados de saúde ${ }^{(6)}$, e, portanto, faz-se necessário o envolvimento da enfermagem na busca deste objetivo.

Nem sempre a rede social de apoio tem o efeito esperado, pois uma rede com poucos membros pode ter limitada possibilidade de atender às necessidades da pessoa ${ }^{(7)}$; a rede social que oferece apoio inadequado, através de conselhos e informações inapropriados pode trazer riscos à pessoa ${ }^{(8)}$; $\mathrm{e}$ nas situações em que os integrantes da rede não reconhecem sua função de apoiadores ${ }^{(9)}$. $\mathrm{O}$ enfermeiro deve estar atento para identificar situações como estas e desenvolver estratégias para estabelecimento e fortalecimento dos vínculos, e ações de educação em saúde compartilhadas.

A compreensão das interações da rede social de apoio permite também que o enfermeiro realize uma autoanálise das suas competências e habilidades, como ser integrante da rede social secundária da pessoa. Isso proporciona a corresponsabilização traduzida num cuidado integral e contínuo, com acionamento, quando necessário, dos diferentes setores institucionais em prol do atendimento às necessidades dos seus clientes.

Embora seja necessário considerar as características positivas das redes sociais de apoio, a estrutura dessas redes, bem como as relações e interações sociais que ocorrem podem funcionar negativamente, causando estresse e conflitos ao prover uma ajuda ineficaz ${ }^{(10)}$. Nesse sentido, apreender situações em que a rede social é descrita como ineficaz nas dimensões estrutural, dinâmica e funcional pode contribuir com o planejamento de estratégias efetivas para diagnosticar e intervir nesses casos. Assim, a presente revisão objetiva avaliar as características da rede social de apoio ineficaz evidenciadas em sua estrutura, funcionalidade e dinâmica.

\section{MÉTODO}

A revisão integrativa é um método de pesquisa que facilita a incorporação de evidências científicas na práti$\mathrm{ca}^{(11)}$. O referencial metodológico seguido foi o proposto por Whittemore e Knaff ${ }^{(12)}$, constituído por seis passos: 1 identificação do tema e seleção da hipótese ou questão de pesquisa para a elaboração da revisão integrativa; 2-estabelecimento de critérios para inclusão e exclusão de estudos/amostragem ou busca na literatura; 3-definição das informações a serem extraídas dos estudos selecionados/ categorização dos estudos; 4-avaliação dos estudos incluídos na revisão integrativa; 5 -interpretação e discussão dos resultados; 6-apresentação da revisão.

No primeiro passo, foi definida a seguinte questão de pesquisa: "Como a rede social de apoio ineficaz tem sido descrita na literatura quanto à sua estrutura, funções e dinâmica?" Os critérios de inclusão determinados no segundo passo foram: artigos originais disponíveis na íntegra em português, inglês e espanhol, que abordassem a rede social de apoio ineficaz, e respondessem a questão de pesquisa. Artigos de revisão narrativa, sistemática ou integrativa, editoriais, cartas ao leitor, notícias, teses, dissertações e anais de 
eventos científicos foram excluídos. Não houve recorte temporal para captação de um número maior de publicações.

O cruzamento dos Descritores em Ciências da Saúde (DeCS) e seus correspondentes em inglês e espanhol Rede Social / Redes Sociais/ Apoio Social / Redes de Apoio Social foi realizado utilizando-se o operador booleano "OR", e estes foram cruzados com o termo "ineficaz" empregando o operador booleano "AND" nas bases de dados CUIDEN, BDENF, Lilacs; e na biblioteca SciELO. Na busca nas bases de dados CINAHL, Scopus e Web of Science foi feito o cruzamento dos MeSH Terms Social Network OR Social Networks OR Social Support AND Ineffective.

A busca e a seleção dos estudos ocorreram em dezembro de 2017, resultando em 2012 publicações encontradas nas seis bases e na biblioteca virtual mencionadas. Em todas elas, os títulos e resumos foram lidos, sendo excluídos os que não atendiam aos critérios de inclusão. Foram pré- -selecionados 112 para leitura na íntegra. Destes, na base Scopus, 19 foram excluídos por abordarem outras temáticas, um pela indisponibilidade de acesso em um dos idiomas determinados para este estudo, e três estavam duplicados, em mais de uma base; na CINAHL, 13 estudos não respondiam à pergunta de pesquisa; todos os artigos da base BDENF e Biblioteca SciELO, não apresentavam correlação com a pergunta dessa revisão; na Web of Science e CUIDEN, 36 e 16 artigos foram eliminados, respectivamente, por não responderem à questão de pesquisa. Na base Lilacs não foram encontrados estudos que correspondessem à pesquisa. Deste modo, 24 artigos compuseram a amostra final (Quadro 1). Para melhor clareza quanto à busca e os motivos de exclusão das publicações, apresenta-se um fluxograma, adaptado da Recomendação PRISMA Principais Itens para Relatar Revisões sistemáticas e Meta-análises ${ }^{(13)}$ (Figura 1).

\begin{tabular}{|c|c|c|c|}
\hline Base de dados & $\begin{array}{l}\text { Estudos encontrados no } \\
\text { cruzamento }\end{array}$ & $\begin{array}{l}\text { Estudos pré-selecionados } \\
\text { para leitura na íntegra }\end{array}$ & $\begin{array}{l}\text { Estudos selecionados para } \\
\text { compor a amostra da revisão }\end{array}$ \\
\hline Scopus & 375 & 23 & 03 \\
\hline CINAHL & 51 & 15 & 02 \\
\hline Web of Science & 1046 & 40 & 04 \\
\hline CUIDEN & 532 & 31 & 15 \\
\hline BDENF & 06 & 02 & 00 \\
\hline Lilacs & 00 & 00 & 00 \\
\hline SciELO & 02 & 01 & 00 \\
\hline TOTAL & 2012 & 112 & 24 \\
\hline
\end{tabular}

Quadro 1 - Seleção dos estudos para a revisão integrativa Fonte: Dados da pesquisa, 2017.

Os 24 estudos foram lidos minuciosamente e, para extração dos dados, empregou-se um instrumento elaborado e refinado por meio da avaliação de sua clareza, abrangência, facilidade de compreensão, extensão e forma de apresentação, por três juízes com experiência no método de revisão integrativa ${ }^{(14)}$. O instrumento consiste numa lista de dados relevantes a serem extraídos dos estudos, com itens referentes à identificação do artigo, referencial teórico/ metodológico, características metodológicas, análise dos dados, resultados, conclusões, implicações para a enfermagem, presença de viés e nível de evidência científica de acordo com a classificação de Melnyk e Fineout-Overholt $t^{(15)}$.

Também foi verificado o rigor metodológico utilizando a ferramenta Critical Appraisal Skills Programme (CASP) (16) específica para cada tipo de estudo, que contém dez itens pontuados de 0 a 1. Os 24 artigos foram classificados de acordo com a pontuação obtida: A (6 a 10) possui viés reduzido, indicado para compor a amostra final da revisão; B (0 a 5) caracterizado de baixo rigor metodológico.

A organização e a discussão das informações evidenciadas nos estudos sobre rede social de apoio ineficaz foram centradas nas dimensões: estrutural, que se refere ao conjunto de laços estabelecidos entre as pessoas e que confere o formato da rede; funcional, representa as trocas de apoio e contenção que ocorrem; dinâmica, compreende a circulação de informações e redistribuição das forças nos pontos de maior tensão - referenciadas pela Teoria de Rede social de Sanicola ${ }^{(1)}$. Estas dimensões serão discutidas de maneira separadas, para que todas as características evidenciadas sejam avaliadas, à luz do referencial teórico escolhido. 


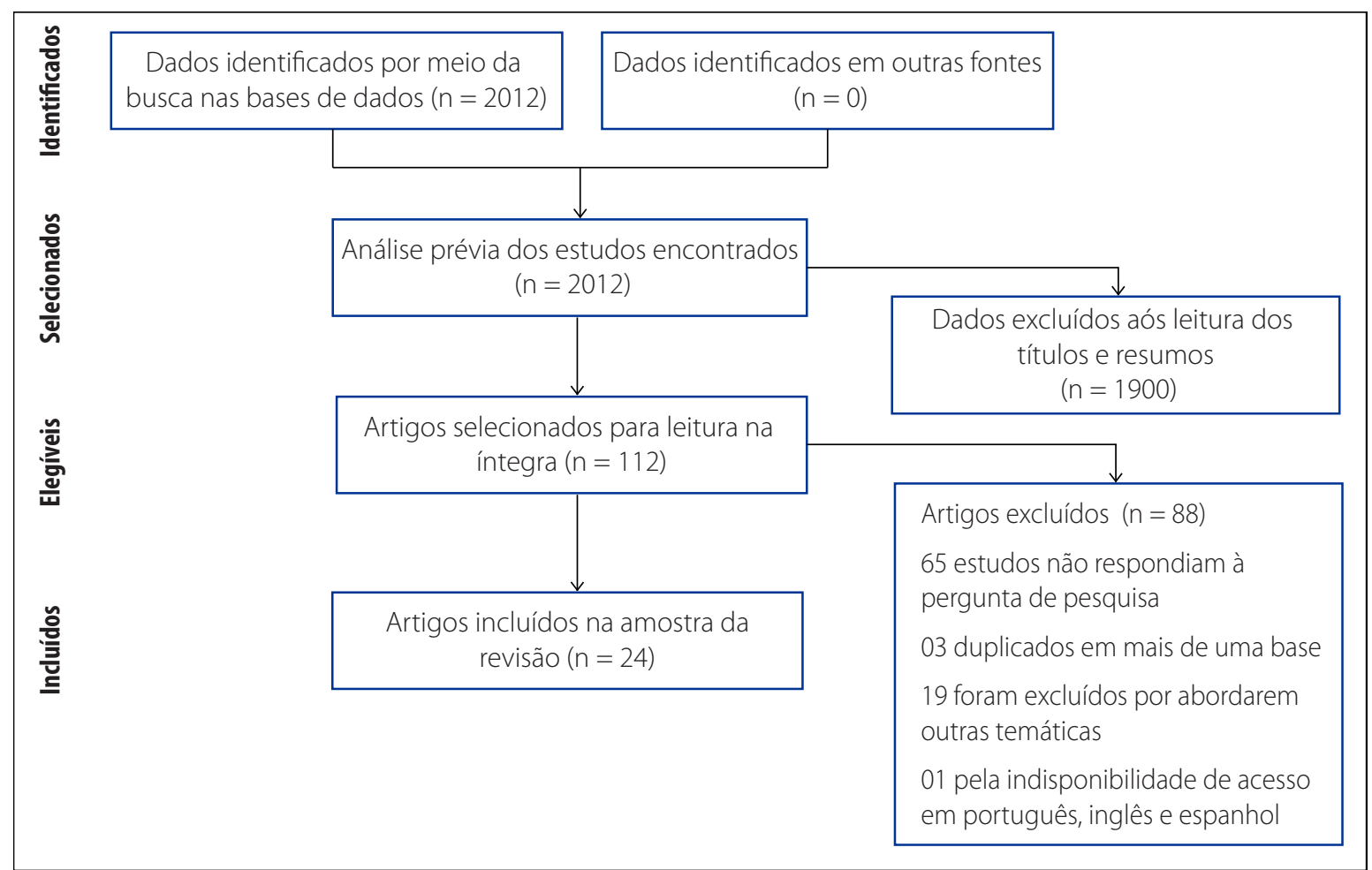

Figura 1 - Fluxograma de busca e seleção dos artigos, adaptado de PRISMA ${ }^{(13)}$

Fonte: Dados da pesquisa, 2017.

\section{RESULTADOS}

A maioria dos artigos selecionados (15), foi encontrada na base de dados CUIDEN ${ }^{(17-31)}$; na Scopus três ${ }^{(32-34)}$; na Web of Science quatro ${ }^{(35-38)}$ e na CINAHL dois ${ }^{(39-40)}$. O idioma predominante foi o português (16), sendo todos originados no Brasi $\left({ }^{(18-31,39-40)}\right.$. Os demais, oito estudos, foram escritos no idioma inglês ${ }^{(17,32-38)}$, tendo como país de origem EUA, com duas publicações ${ }^{(34-35)}$, África do Sul(36), Nova Zelândia(32), Inglaterra ${ }^{(33)}$, Chile ${ }^{(17)}$, Canadá'(37), e Turquia( ${ }^{(38)}$ cada um deles com um artigo.

O ano de edição variou entre 1984 a 2017, sendo a maior parte deles (20) publicados a partir de 2010 $0^{(17-29,31-32,35-36,38-40)} \mathrm{e}$ os anos com maior quantidade de artigos foram $2014^{(21-24)} \mathrm{e}$ $2015^{(18-20,32)}$ com quatro estudos em cada. A área de formação da maioria dos autores principais dos estudos foi a Enfermagem $^{(17-31,37,39-40)}(18)$, seguido de psicologia(34-35,38) $\mathrm{com}$ três estudos. Houve também um autor da área médica ${ }^{(36)}$, um das ciências sociais ${ }^{(33)}$ um da comunicação ${ }^{(32)}$.

Os artigos selecionados, predominantemente, seguiram o método qualitativo ${ }^{(18-28,30-33,35-40)}(21)$, e três, o quantitativo ${ }^{(17,29,34)}$. O nível de evidência ${ }^{(15)}$ de todos eles foi o nível $6^{(17-40)}$. Todos os artigos foram classificados como A por apresentar bom rigor metodológico ${ }^{(16)}$, cuja pontuação re- sultou em 10 pontos para sete dos artigos ${ }^{(17-19,21,24,37,39)}$, nove pontos para onze deles $(20,22,25-26,28-30,32,35-36,40)$, e os demais, seis estudos ${ }^{(23,31,33-34,37-38)}$ obtiveram oito pontos.

A maioria dos estudos (20) abordou tanto a rede primária quanto secundária ${ }^{(18-26,29-37,39-40)}$. Outros três relataram eventos concernentes apenas a rede primária ${ }^{(17,28,38)}$ e um exclusivamente a rede secundária(27).

A dimensão estrutural das redes foi contextualizada em dez estudos ${ }^{(17-18,21-22,25,28,31,34-35,37) ;} 15$ apresentaram características referentes à dimensão funcional(20,24-27,29-33,36-40); e 14 exibiram indicadores da dimensão dinâmica ${ }^{(19,23,25-26,29,31-35,37-40)}$. As características mais encontradas estavam relacionadas às relações frágeis, rompidas ou inexistentes ${ }^{(22,27,34-35,37)}$, presentes na dimensão estrutural; inadequação entre a oferta de apoio e a demanda ${ }^{(26,30,36-37)}$, da dimensão funcional.

Entre os estudos, apenas três evidenciaram características envolvendo as três dimensões da rede social ${ }^{(2,31,37)}$. Outros abordaram apenas uma das dimensões, sendo que cinco deles exclusivamente a dimensão estrutural|(17-18,21-22,28), cinco a dimensão funcional(20,24,27,30,36), e dois unicamente a dimensão dinâmica ${ }^{(19,23)}$. Dos demais estudos, sete relacionaram fatores pertencentes às dimensões funcional e dinâmica ${ }^{(26,29,32-33,38-40)}$, e dois às dimensões estrutural e dinâmica ${ }^{(34-35)}$ (Quadro 2). 


\begin{tabular}{|c|c|c|c|c|c|}
\hline $\begin{array}{c}\text { Autor } \\
\text { Ano } \\
\text { Base de da- } \\
\text { dos }\end{array}$ & Objetivo do estudo & $\begin{array}{l}\text { Tipo de } \\
\text { Rede } \\
\text { social }\end{array}$ & \multicolumn{3}{|c|}{ Características de rede social de apoio ineficaz } \\
\hline $\begin{array}{l}\text { Flores González } \\
\text { et al. }{ }^{(17)} \\
2016 \\
\text { CUIDEN }\end{array}$ & $\begin{array}{l}\text { Determinar o apoio } \\
\text { social em cuidadores } \\
\text { familiares de idosos } \\
\text { dependentes } \\
\text { e sua relação com } \\
\text { características } \\
\text { sociodemográficas. } \\
\end{array}$ & Primária & $\begin{array}{l}\text { - Rede social restrita } \\
\text { (poucos atores) }\end{array}$ & & \\
\hline $\begin{array}{l}\text { Vieira et al. }{ }^{(18)} \\
2015 \\
\text { CUIDEN }\end{array}$ & $\begin{array}{l}\text { Analisar as possibilidades } \\
\text { de ajuda/apoio mediante } \\
\text { o mapeamento e } \\
\text { reconhecimento da rede } \\
\text { social de mulheres que } \\
\text { denunciam o vivido } \\
\text { da violência, em uma } \\
\text { Delegacia de Polícia para a } \\
\text { Mulher. } \\
\end{array}$ & $\begin{array}{l}\text { Primária e } \\
\text { Secundária }\end{array}$ & $\begin{array}{l}\text { - Baixa densidade } \\
\text { da rede } \\
\text { - Baixa amplitude } \\
\text { da rede }\end{array}$ & & \\
\hline $\begin{array}{l}\text { Alvarenga et } \\
\text { al. }^{(19)} \\
2015 \\
\text { CUIDEN }\end{array}$ & $\begin{array}{l}\text { Conhecer a rede } \\
\text { social e o apoio social } \\
\text { disponibilizado ao } \\
\text { cuidador da criança } \\
\text { exposta ao HIV, no período } \\
\text { pós-natal. } \\
\end{array}$ & $\begin{array}{l}\text { Primária e } \\
\text { Secundária }\end{array}$ & & & $\begin{array}{l}\text { - Preconceito } \\
\text { dos integrantes } \\
\text { da rede para } \\
\text { com a pessoa } \\
\text { que precisa do } \\
\text { cuidado }\end{array}$ \\
\hline $\begin{array}{l}\text { Costa et al. }{ }^{(20)} \\
2015 \\
\text { CUIDEN }\end{array}$ & $\begin{array}{l}\text { Analisar as percepções } \\
\text { dos adolescentes sobre } \\
\text { as redes de apoio à suas } \\
\text { necessidades de saúde. }\end{array}$ & $\begin{array}{l}\text { Primária e } \\
\text { Secundária }\end{array}$ & & $\begin{array}{l}\text { - Negligencia as } \\
\text { necessidades } \\
\text { apresentadas pela } \\
\text { pessoa }\end{array}$ & \\
\hline $\begin{array}{l}\text { Silva et al. }{ }^{(21)} \\
2014 \\
\text { CUIDEN }\end{array}$ & $\begin{array}{l}\text { Conhecer a influência } \\
\text { das redes sociais no } \\
\text { itinerário terapêutico de } \\
\text { pessoas acometidas por } \\
\text { úlcera venosa. }\end{array}$ & $\begin{array}{l}\text { Primária e } \\
\text { Secundária }\end{array}$ & $\begin{array}{l}\text { - Dispersão da rede } \\
\text { - Ausência ou } \\
\text { distância dos } \\
\text { familiares }\end{array}$ & & \\
\hline $\begin{array}{l}\text { Braga et al. }{ }^{(22)} \\
2014 \\
\text { CUIDEN }\end{array}$ & $\begin{array}{l}\text { Analisar as percepções } \\
\text { de adolescentes } \\
\text { sobre apoio social na } \\
\text { maternidade. }\end{array}$ & $\begin{array}{l}\text { Primária e } \\
\text { Secundária }\end{array}$ & $\begin{array}{l}\text { - Mapas de rede } \\
\text { com tamanhos } \\
\text { reduzidos } \\
\text { - Densidade frágil } \\
\text { - Lacunas de } \\
\text { dispersão } \\
\text { significativas } \\
\text { - Relações frágeis, } \\
\text { rompidas ou } \\
\text { inexistentes } \\
\end{array}$ & & \\
\hline $\begin{array}{l}\text { Polita et al. }{ }^{(23)} \\
2014 \\
\text { CUIDEN }\end{array}$ & $\begin{array}{l}\text { Analisar a estrutura e } \\
\text { composição das famílias } \\
\text { com crianças com paralisia } \\
\text { cerebral e identificar a } \\
\text { existência } \\
\text { de apoio e rede social que } \\
\text { elas dispõem. }\end{array}$ & $\begin{array}{l}\text { Primária e } \\
\text { Secundária }\end{array}$ & & & - Preconceito \\
\hline
\end{tabular}




\begin{tabular}{|c|c|c|c|c|c|}
\hline $\begin{array}{l}\text { Mazza et al. }{ }^{(24)} \\
2014 \\
\text { CUIDEN }\end{array}$ & $\begin{array}{l}\text { Investigar a influência das } \\
\text { redes sociais de apoio no } \\
\text { processo de amamentação } \\
\text { de nutrizes adolescentes. }\end{array}$ & $\begin{array}{l}\text { Primária e } \\
\text { Secundária }\end{array}$ & & $\begin{array}{l}\text { - Fornecimento } \\
\text { de orientações } \\
\text { inadequadas } \\
\text { - Tentativas de } \\
\text { coagir a pessoa a } \\
\text { ter determinado } \\
\text { comportamento }\end{array}$ & \\
\hline $\begin{array}{l}\text { Araújo et al. }{ }^{(25)} \\
2013 \\
\text { CUIDEN }\end{array}$ & $\begin{array}{l}\text { Analisar as fragilidades } \\
\text { da rede social de } \\
\text { famílias de crianças com } \\
\text { doença crônica. }\end{array}$ & $\begin{array}{l}\text { Primária e } \\
\text { Secundária }\end{array}$ & $\begin{array}{l}\text { - Organização } \\
\text { incipiente da rede } \\
\text { de serviços de } \\
\text { atenção à saúde }\end{array}$ & $\begin{array}{l}\text { - Fornecimento } \\
\text { de apoio } \\
\text { informativo de } \\
\text { forma equivocada, } \\
\text { prejudicando o } \\
\text { enfrentamento da } \\
\text { doença } \\
\text { - Desinteresse pela } \\
\text { demanda do outro } \\
\text { - Indisponibilidade } \\
\text { dos atores da } \\
\text { rede para fornecer } \\
\text { apoio social }\end{array}$ & $\begin{array}{l}\text { - Sobrecarga } \\
\text { do cuidador } \\
\text { principal }\end{array}$ \\
\hline $\begin{array}{l}\text { Sanchez et al. }{ }^{(26)} \\
2012 \\
\text { CUIDEN }\end{array}$ & $\begin{array}{l}\text { Compreender o significado } \\
\text { que a família em situação } \\
\text { de vulnerabilidade social } \\
\text { atribui ao apoio social e à } \\
\text { rede social em sua vivência } \\
\text { com o câncer. }\end{array}$ & $\begin{array}{l}\text { Primária e } \\
\text { Secundária }\end{array}$ & & $\begin{array}{l}\text { - Insuficiência de } \\
\text { apoio instrumental } \\
\text { dos serviços de } \\
\text { saúde } \\
\text { - Falta de visita } \\
\text { domiciliar dos } \\
\text { profissionais de } \\
\text { saúde } \\
\text { - Inadequação entre } \\
\text { a oferta de apoio } \\
\text { e a demanda de } \\
\text { apoio } \\
\text { - Apoio fornecido } \\
\text { de forma não } \\
\text { espontânea }\end{array}$ & $\begin{array}{l}\text { - Rejeição } \\
\text { familiar após } \\
\text { diagnóstico } \\
\text { - Sobrecarga } \\
\text { do familiar } \\
\text { cuidador }\end{array}$ \\
\hline $\begin{array}{l}\text { Faquinello et } \\
\text { al. (27) } \\
2010 \\
\text { CUIDEN }\end{array}$ & $\begin{array}{l}\text { Identificar a percepção } \\
\text { dos hipertensos sobre } \\
\text { as ações da Unidade } \\
\text { Básica de Saúde na } \\
\text { sua rede social de } \\
\text { apoio com relação } \\
\text { ao enfrentamento da } \\
\text { condição crônica da } \\
\text { doença. }\end{array}$ & Secundária & & $\begin{array}{l}\text { - Falta de } \\
\text { acolhimento por } \\
\text { parte dos serviços } \\
\text { de saúde }\end{array}$ & \\
\hline
\end{tabular}




\begin{tabular}{|c|c|c|c|c|c|}
\hline $\begin{array}{l}\text { Di Primio et } \\
\text { al. }{ }^{(28)} \\
2010 \\
\text { CUIDEN }\end{array}$ & $\begin{array}{l}\text { Conhecer os vínculos } \\
\text { apoiadores e a rede } \\
\text { social das famílias } \\
\text { criança portadora de } \\
\text { câncer. }\end{array}$ & Primária & $\begin{array}{l}\text { - Escassez de atores } \\
\text { na rede que } \\
\text { possam ser fonte } \\
\text { de apoio } \\
\text { - Fragilização } \\
\text { de vínculos } \\
\text { anteriormente } \\
\text { estabelecidos }\end{array}$ & & \\
\hline $\begin{array}{l}\text { Sousa et al. }{ }^{(29)} \\
2010 \\
\text { CUIDEN }\end{array}$ & $\begin{array}{l}\text { Identificar a percepção de } \\
\text { disponibilidade e oferta } \\
\text { de apoio social informal e } \\
\text { formal entre idosas de uma } \\
\text { localidade de baixa renda } \\
\text { do Município do Rio de } \\
\text { Janeiro. }\end{array}$ & $\begin{array}{l}\text { Primária e } \\
\text { Secundária }\end{array}$ & & $\begin{array}{l}\text { - A pessoa oferta } \\
\text { muito mais apoio } \\
\text { para a sua rede do } \\
\text { que recebe dos } \\
\text { atores da rede }\end{array}$ & $\begin{array}{l}\text { - O apoio } \\
\text { fornecido pela } \\
\text { pessoa para } \\
\text { a rede não } \\
\text { é valorizado } \\
\text { pelos atores }\end{array}$ \\
\hline $\begin{array}{l}\text { Simioni et al. }{ }^{(30)} \\
2008 \\
\text { CUIDEN }\end{array}$ & $\begin{array}{l}\text { Conhecer a percepção das } \\
\text { mães de crianças nascidas } \\
\text { prematuras acerca do } \\
\text { apoio social recebido no } \\
\text { domicílio para o cuidado } \\
\text { das mesmas. }\end{array}$ & $\begin{array}{l}\text { Primária e } \\
\text { Secundária }\end{array}$ & & $\begin{array}{l}\text { - Distanciamento } \\
\text { por parte dos } \\
\text { profissionais da } \\
\text { saúde do cuidado } \\
\text { comunitário } \\
\text { - Falta de alguém } \\
\text { para conversar } \\
\text { e contar seus } \\
\text { medos, de uma } \\
\text { pessoa que a } \\
\text { fizesse sentir-se } \\
\text { querida e apoiada } \\
\text { - Não suprimento } \\
\text { das expectativas } \\
\text { da pessoa por } \\
\text { parte da rede } \\
\text { social }\end{array}$ & \\
\hline $\begin{array}{l}\text { Albuquer- } \\
\text { que Netto et } \\
\text { al. }^{(31)} \\
2017 \\
\text { CUIDEN }\end{array}$ & $\begin{array}{l}\text { Analisar o isolamento } \\
\text { social de mulheres em } \\
\text { situação de violência } \\
\text { pelo parceiro íntimo. }\end{array}$ & $\begin{array}{l}\text { Primária e } \\
\text { Secundária }\end{array}$ & - Isolamento social & $\begin{array}{l}\text { - Baixa qualidade } \\
\text { dos membros da } \\
\text { rede }\end{array}$ & $\begin{array}{l}\text { - Vulnerabili- } \\
\text { dade social }\end{array}$ \\
\hline $\begin{array}{l}\text { Brown et al. }{ }^{(32)} \\
2015 \\
\text { Scopus }\end{array}$ & $\begin{array}{l}\text { Explorar, à luz da teoria } \\
\text { da dialética relacional, as } \\
\text { tensões de comunicação } \\
\text { experienciadas por } \\
\text { homens de uma lista } \\
\text { de espera de biópsia } \\
\text { de próstata e o } \\
\text { gerenciamento deles } \\
\text { sobre essas tensões } \\
\text { através de suas redes de } \\
\text { comunicação. }\end{array}$ & $\begin{array}{l}\text { Primária e } \\
\text { Secundária }\end{array}$ & & $\begin{array}{l}\text { - Preferem ser } \\
\text { independentes e } \\
\text { fazer suas próprias } \\
\text { coisas a aceitar } \\
\text { ajuda }\end{array}$ & $\begin{array}{l}\text { - Entende a } \\
\text { preocupação } \\
\text { dos outros ou } \\
\text { ter que contar } \\
\text { sobre sua } \\
\text { doença como } \\
\text { uma invasão de } \\
\text { privacidade }\end{array}$ \\
\hline
\end{tabular}




\begin{tabular}{|c|c|c|c|c|c|}
\hline $\begin{array}{l}\text { Hubert } \\
2006 \\
\text { Scopus }\end{array}$ & $\begin{array}{l}\text { Identificar os tipos e a } \\
\text { adequação dos serviços } \\
\text { recebidos pelos cuidadores } \\
\text { de familiares de pessoas } \\
\text { negras com deficiências } \\
\text { de aprendizagem e grupos } \\
\text { étnicos minoritários; } \\
\text { Identificar os serviços } \\
\text { fundamentais no } \\
\text { atendimento das } \\
\text { necessidades desses } \\
\text { cuidadores; } \\
\text { Verificar o impacto social, } \\
\text { cultural e possíveis } \\
\text { barreiras de comunicação } \\
\text { no acesso aos serviços } \\
\text { oferecidos. }\end{array}$ & $\begin{array}{l}\text { Primária e } \\
\text { Secundária }\end{array}$ & & $\begin{array}{l}\text { - Falta de tempo } \\
\text { dos membros da } \\
\text { rede para ajudar }\end{array}$ & $\begin{array}{l}\text { - Integrantes da } \\
\text { rede que antes } \\
\text { eram também } \\
\text { fontes de apoio } \\
\text { instrumental } \\
\text { e atualmente } \\
\text { só podem } \\
\text { oferecer apoio } \\
\text { emocional } \\
\text { - Integrantes } \\
\text { da rede que } \\
\text { se afastaram } \\
\text { depois da } \\
\text { doença, pois } \\
\text { a situação da } \\
\text { pessoa torna- } \\
\text { se deprimente } \\
\text { e eles não } \\
\text { querem ter } \\
\text { contato }\end{array}$ \\
\hline $\begin{array}{l}\text { Mcfarlane et } \\
\text { al. }{ }^{(34)} \\
1984 \\
\text { Scopus }\end{array}$ & $\begin{array}{l}\text { Examinar amostras } \\
\text { de indivíduos com } \\
\text { apoio social útil e inútil, } \\
\text { identificados } \\
\text { em um estudo } \\
\text { longitudinal de eventos } \\
\text { estressantes, apoios } \\
\text { sociais e saúde. }\end{array}$ & $\begin{array}{l}\text { Primária e } \\
\text { Secundária }\end{array}$ & $\begin{array}{l}\text { - Maior frequência } \\
\text { de contatos } \\
\text { com relações } \\
\text { menos íntimas } \\
\text { (amigos, colegas } \\
\text { de trabalho, } \\
\text { profissionais) e } \\
\text { menos contato } \\
\text { com os mais } \\
\text { íntimos (família) } \\
\text { - Redes de tamanho } \\
\text { maior } \\
\text { - Poucas relações } \\
\text { recíprocas }\end{array}$ & & $\begin{array}{l}\text { - Dificuldade } \\
\text { de relaciona- } \\
\text { mento com } \\
\text { algum membro } \\
\text { importante do } \\
\text { núcleo da rede } \\
\text { (família) }\end{array}$ \\
\hline $\begin{array}{l}\text { Roos et al. }{ }^{(35)} \\
2012 \\
\text { Web of Science }\end{array}$ & $\begin{array}{l}\text { Explorar as experiências } \\
\text { de solidão dos } \\
\text { idosos no cuidado } \\
\text { institucionalizado. }\end{array}$ & $\begin{array}{l}\text { Primária e } \\
\text { Secundária }\end{array}$ & $\begin{array}{l}\text { - Ausência de } \\
\text { interações } \\
\text { interpessoais } \\
\text { significativas } \\
\text { - Distância física } \\
\text { dos atores da rede } \\
\text { social de apoio }\end{array}$ & & $\begin{array}{l}\text { - Invasão de } \\
\text { privacidade }\end{array}$ \\
\hline
\end{tabular}




\begin{tabular}{|c|c|c|c|c|c|}
\hline $\begin{array}{l}\text { Wong et al. }{ }^{(36)} \\
2010 \\
\text { Web of Science }\end{array}$ & $\begin{array}{l}\text { Analisar o apoio social } \\
\text { percebido entre crianças } \\
\text { de pais diagnosticados } \\
\text { com câncer }\end{array}$ & $\begin{array}{l}\text { Primária e } \\
\text { Secundária }\end{array}$ & & $\begin{array}{l}\text { - As necessidades } \\
\text { de apoio da } \\
\text { pessoa não são } \\
\text { supridas pela sua } \\
\text { rede social } \\
\text { - Discrepância entre } \\
\text { o apoio social } \\
\text { esperado e o } \\
\text { recebido } \\
\text { - O apoio é } \\
\text { oferecido sem } \\
\text { conexão com as } \\
\text { necessidades da } \\
\text { pessoa }\end{array}$ & \\
\hline $\begin{array}{l}\text { Neufeld et al. }{ }^{(37)} \\
2007 \\
\text { Web of Science }\end{array}$ & $\begin{array}{l}\text { Descrever tipos de } \\
\text { interações de não- } \\
\text { suporte percebidas por } \\
59 \text { mulheres cuidadoras } \\
\text { familiares em } \\
\text { quatro situações } \\
\text { diversas. } \\
\text { (Prematuridade/crianças } \\
\text { com doenças crônicas/ } \\
\text { adultos com câncer/ } \\
\text { adultos com demência) }\end{array}$ & $\begin{array}{l}\text { Primária e } \\
\text { Secundária }\end{array}$ & $\begin{array}{l}\text { - Falta de conexão } \\
\text { com amigos e } \\
\text { familiares }\end{array}$ & $\begin{array}{l}\text { - Aconselhamento } \\
\text { indesejável } \\
\text { - Apoio esperado que } \\
\text { não se materializou } \\
\text { - Consumo de } \\
\text { recursos materiais } \\
\text { - Esforços destinados } \\
\text { a ajudar, mas } \\
\text { percebidos como } \\
\text { inúteis } \\
\text { - Reciprocidade } \\
\text { inadequada } \\
\text { - Recusa dos } \\
\text { membros da rede } \\
\text { oferecer apoio } \\
\text { - Oferecimento } \\
\text { de informações } \\
\text { inadequadas } \\
\text { - Conselhos } \\
\text { inapropriados }\end{array}$ & $\begin{array}{l}\text { - Invasão de } \\
\text { privacidade } \\
\text { - Excessivas } \\
\text { interações } \\
\text { ineficazes ou sem } \\
\text { finalidade de } \\
\text { apoio } \\
\text { - Conflitos } \\
\text { - Omissão de } \\
\text { informações } \\
\text { - Falta de } \\
\text { sensibilida-de } \\
\text { cultural } \\
\text { - Interações } \\
\text { conflituosas } \\
\text { - Preconceito } \\
\text { - O serviço de } \\
\text { ajuda é restrito } \\
\text { ou inexistente }\end{array}$ \\
\hline $\begin{array}{l}\text { Karanci et al. }{ }^{(38)} \\
2017 \\
\text { Web of Science }\end{array}$ & $\begin{array}{l}\text { Examinar o que é } \\
\text { percebido como apoio } \\
\text { útil e inútil dos membros } \\
\text { das redes sociais naturais } \\
\text { empessoas turcas com } \\
\text { esquizofrenia }\end{array}$ & Primária & & $\begin{array}{l}\text {-Comportamentos } \\
\text { intrusivos }\end{array}$ & $\begin{array}{l}\text { - Atitudes } \\
\text { preconceitu- } \\
\text { osas } \\
\text { - Conflitos }\end{array}$ \\
\hline $\begin{array}{l}\text { Borges et al. }{ }^{(39)} \\
2016 \\
\text { CINAHL }\end{array}$ & $\begin{array}{l}\text { Conhecer a rede e o } \\
\text { apoio social da pessoa } \\
\text { que vivencia o processo } \\
\text { de adoecimento e o } \\
\text { transplante renal. }\end{array}$ & $\begin{array}{l}\text { Primária e } \\
\text { Secundária }\end{array}$ & & $\begin{array}{l}\text { - Falta de apoio } \\
\text { informativo }\end{array}$ & $\begin{array}{l}\text { - Impessoali- dade } \\
\text { das relações } \\
\text { profissional- } \\
\text { paciente }\end{array}$ \\
\hline
\end{tabular}




\begin{tabular}{|c|c|c|c|c|}
\hline $\begin{array}{l}\text { Pandini et al. }{ }^{(40)} \\
2016 \text { CINAHL }\end{array}$ & $\begin{array}{l}\text { Apreender as vivências } \\
\text { de famílias em relação ao } \\
\text { familiar usuário de drogas } \\
\text { e conhecer aspectos de } \\
\text { sua rede social. }\end{array}$ & $\begin{array}{l}\text { Primária e } \\
\text { Secundária }\end{array}$ & $\begin{array}{l}\text { - Grande demanda de } \\
\text { apoio } \\
\text { - Falta de } \\
\text { conhecimento } \\
\text { sobre o problema da } \\
\text { pessoa } \\
\text { - Banalização do } \\
\text { problema da pessoa }\end{array}$ & $\begin{array}{l}\text { - Preconceito } \\
\text { - Sobrecarga do } \\
\text { cuidador }\end{array}$ \\
\hline
\end{tabular}

Quadro 2 - Características de Rede social de apoio ineficaz encontradas nos estudos Fonte: Dados da pesquisa, 2017.

\section{DISCUSSÃO}

A análise dos artigos selecionados permite constatar que no Brasil têm sido realizados estudos de qualidade metodológica sobre rede social, e estes foram localizados na base de dados CUIDEN, na qual estão indexados relevantes periódicos de Enfermagem do país citado, possibilitando a divulgação do conhecimento científico produzido a partir da atuação dos enfermeiros na temática.

O maior número de artigos utilizou o método qualitativo, como era o esperado, uma vez que as relações interpessoais que ocorrem dentro das redes são melhor apreendidas em estudos que permitem compreender e interpretar fenômenos relacionados a vivências e ação social ${ }^{(41)}$. Ressalta-se que as pesquisas qualitativas respondem às questões hermenêuticas e não têm a pretensão de oferecer explicações exatas, de ordem numérica. As evidências científicas qualitativas estão centradas na apreensão das vivências individuais e coletiva compartilhadas, as quais permitem explicar à práxis da pessoa, revelada na complexa tarefa humana de tentar entender o outro para poder ajudá-lo(42) - sendo esse o objetivo das pesquisas com rede social.

Os estudos trataram da investigação tanto das redes primárias quanto secundárias, contudo, a quantidade de características de rede social ineficaz nas redes secundárias foi menos numerosa, provavelmente, devido ao fato das relações sociais mais significativas serem em geral estabelecidas com a rede primária, assim, sua ineficácia é sentida mais intensamente pela pessoa. As redes secundárias evidenciadas foram os serviços e as instituições de saúde, na ótica do não atendimento às necessidades apresentadas pelos clientes.

A avaliação das características da rede social de apoio ineficaz concernentes as três dimensões da rede social descritas por Sanicola(1) - estrutural, funcional e dinâmica serão abordadas a seguir.

\section{Dimensão estrutural}

A ineficácia relacionada ao tamanho das redes foi abordada em alguns estudos ${ }^{(17-18,22,27,31,34)}$, sendo que em quatro deles percebeu-se a negatividade das redes compostas por um número reduzido de participantes ${ }^{(17-18,22,27)}$, e em um outro ${ }^{(34)}$ a rede mais ampla, com mais integrantes. $\mathrm{Na}$ prática, as redes médias são mais efetivas do que as pequenas e as numerosas em pessoas. Nas amplas redes, a grande quantidade de integrantes pode gerar uma impessoalidade e a impressão de que alguém já pode ter assumido o cuidado da pessoa; nas redes pequenas por sua vez, é possível a sobrecarga dos poucos membros e a tensão de longa duração, que afasta as pessoas que não querem se envolver e apoiar ${ }^{(43)}$.

Esse envolvimento pode surgir também das relações entre os demais membros da rede, independente da pessoa, sendo referida como densidade, que reflete a trama de relações entre os demais atores da rede e a baixa interação entre eles pode reduzir o seu efeito cotejador. Tal efeito permite que os integrantes da rede discutam entre si as situações da vida da pessoa, por exemplo, uma mudança de hábito repentina que pode inspirar cuidados ${ }^{(43)}$. Essa problemática da baixa densidade das redes foi verificada nos estudos de Viei$r a^{(18)}$ e Braga ${ }^{(22)}$. Outro fator pertinente à densidade da rede é a dispersão(21,35), que contempla a distância geográfica entre os membros, afetando o acesso ao apoio, bem como a eficácia de atuação rápida em situações de crise.

A ineficácia da rede social de apoio quanto à composição pode ser demonstrada por meio das relações frágeis, rompidas ou inexistentes ${ }^{(22,27,34-35,37)}$, e também nos casos em que há maior frequência de contatos com relações menos íntimas ${ }^{(34,37)}$ em detrimento das estabelecidas (ou não) com amigos e familiares. A diversificação dessa composição é importante para uma melhor flexibilidade e atendimento mais efetivo das necessidades ${ }^{(43)}$. É fundamental que haja o intercâmbio de informações e forças entre os círculos da 
rede, portanto, ter laços constituídos apenas com pessoas de características homogêneas ou do mesmo grupo social é uma característica que a define como ineficaz.

Essa conformação estrutural da rede social, que envolve os membros participantes e a qualidade dos laços estabelecidos entre eles; distância/proximidade afetiva e física; densidade; amplitude; homogeneidade; relações existentes entre a rede primária e secundária, deve ser adequadamente identificada e reconhecida, pelo enfermeiro ou outro profissional, que não tente sobrepor suas convicções à rede. Esse reconhecimento compartilhado proporciona o entendimento dos acontecimentos e a possível atribuição desses fatos à própria conformação da rede social, podendo ser um ponto de partida na busca de soluções em conjunto(1).

No caso de redes secundárias formais, a organização incipiente das instituições para atender as necessidades dos clientes ${ }^{(25,30,33,37)}$ foi identificada, pois a articulação em rede dos serviços de saúde e demais setores de atendimento às demandas da população é necessária para garantir o acesso e a continuidade do cuidado ao cliente, família e coletividade ${ }^{(44)}$.

\section{Dimensão funcional}

As funções das redes refletem o intercâmbio interpessoal que ocorre nas relações sociais, as quais podem ser verificadas quando são realizadas as trocas de apoio e também por ações que permitem efeito contrário do que se quer alcançar por meio da contenção(43). Assim, coagir a pessoa a ter determinado comportamento(24), ainda que seja aparentemente para o seu bem, é classificado como um apoio negativo e ineficaz ${ }^{(45-46)}$.

Atitudes de pressionar a determinados comportamentos considerados positivos podem ser advindas tanto dos membros da rede social primária quanto dos enfermeiros e demais profissionais responsáveis pelo cuidado. Uma das maneiras de debelar esse comportamento é estar disposto a criar vínculos para conhecer e respeitar o cotidiano e a cultura das famílias e redes sociais, identificando fragilidades e potencialidades. A partir dessa inserção no contexto da rede social e da responsabilidade mútua entre profissional-usuário, pode-se buscar em conjunto o bem-estar, sem regras e imposições, mas construindo o cuidado humanizado(47).

O provimento de apoio informativo - oferecimento de conselhos e sugestões referentes ao desempenho da pessoa $^{(48)}$ - inadequado ou insuficiente ${ }^{(24,37,39)}$ pode dificultar o entendimento da real situação e prejudicar o enfrentamento da situação adversa ${ }^{(25,49)}$. Esse apoio, enquanto função da rede, pode ser decisivo nos resultados de saúde das pessoas, por exemplo - uma mãe no processo de amamentação do seu primeiro filho precisa das informa- ções e conselhos de pessoas de sua rede — quando essas ações contêm mitos e tabus podem ser transformadas em apoio ineficaz.

Quando a rede negligencia as necessidades da pessoa ${ }^{(20,25,40)}$ ou não se mostra disponível para oferecer apoio social ${ }^{(25,33,37)}$, seja ele emocional na rede primária( ${ }^{(30)} \mathrm{com}$ demonstrações de empatia que geram sentimentos de pertença, ou acolhimento nas redes secundárias ${ }^{(28)}$, pode ser caracterizada como ineficaz, pois, reflete a fragilização dos vínculos pessoais e institucionais e a falta de interesse pela demanda do outro(50). Se o apoio for oferecido de forma não espontânea ${ }^{(26)}$, a pessoa pode abstrair aquela situação como um incômodo e se negar a receber a ajuda, visto que a partir das interações que acontecem os indivíduos tomam decisões sobre a sua conduta ${ }^{(51)}$.

A inadequação entre a oferta e a demanda de apoio(25,30,36-37) é evidenciada em situações nas quais 0 apoio oferecido não atende às expectativas da pessoa, seja pelo fato de não haver sincronia na visão do problema, e/ou por objetivos diferentes quanto ao apoio. Isto pode acontecer quando uma pessoa deseja receber apoio emocional sem críticas, mas a rede social insiste na sua mudança de comportamento(37). Tal situação pode levar a um impasse que gere até mesmo rompimento de relações, pois a pessoa necessita e espera o sentimento de ser apoiado e de pertencer ao grupo, no entanto, a sua rede não atende às expectativas.

No contexto da dimensão funcional da rede social de apoio ineficaz, cabe ao enfermeiro identificar os membros que prestam algum tipo de ajuda, ou de contenção, e se estes são capazes de suprir todo apoio demandado ou estão sobrecarregados. Também é necessário verificar o grau de simetria das relações, os tipos de apoio oferecidos, sua relevância e qualidade, bem como seus efeitos na autoestima e psicológico da pessoa ${ }^{(1)}$. A partir disso, o profissional pode planejar a assistência com o propósito de fortalecer os vínculos existentes, trabalhar em conjunto para superar atitudes negativas, e ativar outras possíveis fontes de apoio.

\section{Dimensão dinâmica}

A dinâmica das redes refere-se ao movimento de forças que se distribuem e redistribuem na trama das relações sociais no fluxo contínuo dos pontos de maior tensão, e são deslocadas devido a acontecimentos e conflitos ${ }^{(1)}$. Assim, a sobrecarga do cuidador principal ${ }^{(25-27,40)}$ causa uma alteração na dinâmica das redes que pode confluir tanto à reorganização das forças para que outros atores assumam a responsabilidade, quanto ao abandono da pessoa que necessita do cuidado. 
Situações inesperadas, como mudança de função de algum integrante, podem ocorrer no momento em que uma pessoa que prestava os apoios emocional e instrumental, passa a oferecer somente o apoio emocional ${ }^{(33)}$. Essa transformação pode alterar a dinâmica das redes no sentido do não fornecimento de um apoio com o qual antes se podia contar.

A invasão da privacidade ${ }^{(32,35,37-38)}$ e o preconceito $(19,23,26,40)$ de membros da rede relacionado à situação da pessoa que necessita do apoio pode decorrer de rejeição após o diagnóstico do problema ${ }^{(26)}$ ou pelo estigma intrincado a determinadas condições. Tal atitude desencadeia a falta de comprometimento com o outro, o afastamento das pessoas e dispersão de forças que deveriam ser direcionadas a resolução ou amenização do problema apresentado.

Eventos críticos que podem vir a acontecer - conflitos entre membros da rede ${ }^{(37-38)}$ - levam a desgaste ou rupturas de relações, o que torna evidente a interligação das dimensões da rede, pois uma alteração na dinâmica modifica a estrutura que por sua vez modela a funcionalidade.

A análise da dinâmica da rede social pressupõe que o enfermeiro tenha sensibilidade para entender o significado atribuído às diversas relações, e a compreensão dos movimentos entre o individualismo e a partilha de necessidades. Ao conhecer o cotidiano da rede, ele pode identificar a localização e distribuição das forças existentes, que possibilitam a redefinição da rede frente a possíveis eventos críticos $^{(1)}$.

Os acontecimentos cotidianos e excepcionais que se produzem nas redes the conferem o caráter mutável, dinâmico e circular. Devido a essa característica, as redes podem ser mobilizadas e os laços fortalecidos em busca de novas funcionalidades e da corresponsabilização pela demanda do outro.

Esse atributo permite ao enfermeiro, inicialmente se reconhecer como membro da rede social secundária da pessoa a quem cuida, e ser atuante no oferecimento do apoio necessário, contribuindo para a sua autonomia. Mais do que integrante da rede, o enfermeiro pode ser um mobilizador das redes primárias e secundárias. Ao identificar indicadores de uma rede social ineficaz nas dimensões estrutural, funcional e dinâmica, ele pode promover as relações interpessoais da pessoa, família e coletividade na realização do cuidado integral.

\section{口 CONSIDERAÇÕES FINAIS}

Os indicadores de rede social ineficaz, descritos na literatura analisada, envolveram a dimensão estrutural da rede, denotando situações referentes ao seu tamanho, densidade, composição e homogeneidade, fragilidade dos laços e organização incipiente das redes secundárias; na dimensão funcional foi percebido o fornecimento de apoio social inadequado, insuficiente ou não correspondente às expectativas da pessoa, como também a falta de acolhimento nos serviços de saúde, e encorajamento de comportamentos de risco; a dimensão da dinâmica das redes sociais de apoio ineficaz apresentou características de sobrecarga do cuidador principal, preconceito, invasão de privacidade e mudanças nas funções de apoio de alguns membros.

Os enfermeiros e demais profissionais da saúde, no cuidado a pessoa, família e coletividade devem estar atentos à ineficácia da rede social, que pode levar ao agravamento ou perduração da condição negativa à vida. Esse estudo contribui instrumentalizando-os com informações chave para que, a partir do reconhecimento da rede social ineficaz, possa desenvolver ações de fortalecimento dos vínculos e intervenções educacionais para alcançar resultados saudáveis.

Tais eventos encontrados na literatura podem ser entendidos como antecedentes ou consequentes do fenômeno de enfermagem denominado Rede social de apoio ineficaz, relevante por sua interferência no cuidado, e necessário ser adequadamente reconhecido e qualificado. Os dados dessa revisão reúnem características que podem servir como base para o ensino do processo de enfermagem centrado no contexto social, e para futuras pesquisas na temática, que levem em consideração também o caráter e repercussões negativas das redes sociais.

Assim, são recomendados estudos que contribuam para uma identificação adequada do fenômeno de enfermagem rede social de apoio ineficaz, a exemplo de pesquisas para validação diagnóstica, que são essenciais ao processo de enfermagem ao contribuir para a segunda etapa, a qual é base para o desenvolvimento de intervenções de enfermagem adequadas e relevantes às reais necessidades dos atores da rede social de apoio.

\section{口 REFERÊNCIAS}

1. Sanicola L. As dinâmicas de rede e o trabalho social. São Paulo: Veras Editora; 2015.

2. Haines VA, Beggs JJ, Hurlbert JS. Exploring the structural contexts of the support process: Social networks, social statuses, social support, and psychological distress. Adv Med Sociol 2002;8:269-92.

3. Faber AD, Wasserman S. Social support and social networks: synthesis and review. Adv Med Sociol. 2002;8:29-72.

4. Costa RF, Zeitoune RCG, Queiroz MVO, García CIG, García MJR. Redes de apoio ao adolescente no contexto do cuidado à saúde: interface entre saúde, família e educação. Rev Esc Enferm USP. 2015;49(5):741-7.

5. Gonçalves TR. Avaliação de apoio social em estudos brasileiros: aspectos conceituais e instrumentos. Cienc Saude Coletiva. 2011;16(3):1755-69. 
6. Haber MG, Cohen JL, Lucas T, Baltes BB. The relationship between self-reported received and perceived social support: a meta-analytic review. Am J Community Psychol. 2007;39(1-2):133-44.

7. Alvarenga MRM, Oliveira MADC, Domingues MAR, Amendola F, Faccenda 0. Rede de suporte social do idoso atendido por equipes de Saúde da Família. Ciênc Saúde Coletiva. 2011;16(5):2603-11.

8. Schmied V, Beake S, Sheehan A, McCourt C, Dykes F. Women's perceptions and experiences of breastfeeding support: a metasynthesis. Birth. 2011;38(1):49-60.

9. Prates LA, Schmalfuss JM, Lipinski JM. Rede de apoio social de puérperas na prática da amamentação. Esc Anna Nery. 2015;19(2):310-5.

10. Rooks KS, Pietromonaco P. Close relationships: ties that heal or ties that bind? In: Jones WH; Perlman D (editors). Advances in Personal Relationships. Greenwich, CT: JAI Press; 1987. v. 1, p. 1-35.

11. Mendes KDS, Silveira RCCP, Galvão CM. Revisão integrativa: método de pesquisa para a incorporação de evidências na saúde e na enfermagem. Texto Contexto Enferm. 2008;17(4):758-64.

12. Whittemore $R$, Knafl K. The integrative review: updated methodology. J Adv Nurs. 2005;52(5):546-53.

13. Moher D, Liberati A, Tetzlaff J, Altman DG. The PRISMA Group. Preferred reporting items for systematic reviews and meta-analyses: the PRISMA Statement. PLoS Med. 2009;6(7):e1000097.

14. Chaves ECL, Carvalho EC, Hass VJ. Validação do diagnóstico de enfermagem Angústia Espiritual: análise por especialistas. Acta Paul Enferm. 2010;23(2):26470.

15. Melnyk BM, Fineout-Overholt E. Making the case for evidence-based practice. In: Melnyk BM, Fineout-OverholtE. Evidence based practice in nursing \& healthcare: a guide to best practice. Philadelphia: Lippincot Williams \& Wilkins; 2005. p. 3-24.

16. Critical Appraisal Skills Programme [Internet]. Oxford: CASP; c2017[cited 2017 Dec 02]. CASP Checklists; [about 6 screens]. Available from: https://casp-uk. net/casp-tools-checklists/.

17. Flores González E, Seguel Palma F. Functional social support in family caregivers of elderly adults with severe dependence. Invest Educ Enferm. 2016;34(1):6873.

18. Vieira LB, Souza IEO, Tocantins FR, Pina-Roche F. Support to women who denounce experiences of violence based on her social network. Rev Latino-Am Enfermagem. 2015;23(5):865-73.

19. Alvarenga WA, Galvão MTG, Nascimento LC, Beretta MIR, Dupas G. Rede social fragilizada: a experiência do cuidador da criança nascida exposta ao HIV. Texto Contexto Enferm. 2015;24(3):775-83.

20. Costa RF, Zeitoune RCG, Queiroz MV0, Gómez García Cl, Ruiz García MJ. Redes de apoio ao adolescente no contexto do cuidado à saúde: interface entre saúde, família e educação. Rev Esc Enferm USP. 2015;49(5):741-7.

21. Silva DC, Budó MLD, Schimith MD, Torres GV, Durgante VL, Rizzatti SJS. Influence of social networks on the therapeutic itineraries of people with venous ulcer. Rev Gaúcha Enferm. 2014;35(3):90-6.

22. Braga IF, Oliveira WA, Spanó AMN, Nunes MR, Silva MAI. Percepções de adolescentes sobre 0 apoio social na maternidade no contexto da atenção primária. Esc Anna Nery. 2014;18(3):448-55.

23. Polita NB, Tacla MTGM. Rede e apoio social às famílias de crianças com paralisia cerebral. Esc Anna Nery. 2014;18(1):75-81.

24. Mazza VA, Nunes RCT, Tararthuch RZP, Alexandre AMC, Patel JM. Influência das redes sociais de apoio para nutrizes adolescentes no processo de amamentação. Cogitare Enferm. 2014;19(2):254-60.
25. Araújo YB, Reichert APS, Vasconcelos MGL, Collet N. Fragilidade da rede social de famílias de crianças com doença crônica. Rev Bras Enferm. 2013;66(5):675-81.

26. Sanchez KOL, Ferreira NMLA. 0 apoio social para a família do doente com câncer em situação de pobreza. Texto Contexto Enferm. 2012;21(4):792-9.

27. Faquinello P, Carreira L, Marcon SS. A unidade básica de saúde e sua função na rede de apoio social ao hipertenso. Texto Contexto Enferm. 2010;19(4):736-44.

28. Di Primio A0, Schwartz E, Bielemann VLM, Burille A, Zillmer JGV, Feijó AM. Rede social e vínculos apoiadores das famílias de crianças com câncer. Texto Contexto Enferm. 2010;19(2):334-42.

29. Sousa Al, Silver LD, Griep RH. Apoio social entre idosas de uma localidade de baixa renda no munícipio do Rio de Janeiro. Acta Paul Enferm. 2010;23(5):625-31.

30. Simioni AS, Geib LTC. Percepção materna quanto ao apoio social recebido no cuidado às crianças prematuras no domicílio. Rev Bras Enferm. 2008;61(5):545-51.

31. Albuquerque Netto L, Moura MAV, Queiroz ABA, Leite FMC, Silva GF. Isolamento de mulheres em situação de violência pelo parceiro íntimo: uma condição em redes sociais. Esc Anna Nery 2017;21(1):e20170007.

32. Brown D, Oetzel J. Men's use of networks to manage communication tensions related to a potential diagnosis of prostate cancer. Eur J Oncol Nurs. 2016;20:106-12.

33. Hubert J. Family carers' views of services for people with learning disabilities from Black and minority ethnic groups: a qualitative study of 30 families in a south London borough. Disabil Soc. 2006;21(3):259-72.

34. McFarlane AH, Norman GR, Streiner DL, Roy RG. Characteristics and correlates of effective and ineffective social supports. J Psychosom Res. 1984;28(6):501-10.

35. Roos V, Malan L. The role of context and the interpersonal experience of loneliness among older people in a residential care facility. Glob Health Action. 2012;5.

36. Wong M, Ratner J, Gladstone KA, Davtyan A, Koopman C. Children's perceived social support after a parent is diagnosed with cancer. I Clin Psychol Med Settings. 2010;17(2):77-86.

37. Neufeld A, Harrison MJ, Hughes K, Stewart M. Non-supportive interactions in the experience of women family caregivers. Health Soc Care Community. 2007;15(6):530-41.

38. Karanci NA, Gök AC, Yıldıım B, Borhan N. Social support perceptions of Turkish people with schizophrenia: what helps and what doesn't help. Int J Soc Psychiatry. 2017;63(7):657-65.

39. Borges DCS, Furino FO, Barbieri MC, Souza ROD, Alvarenga WA, Dupas G. The social network and support of kidney transplantees. Rev Gaúcha Enferm. 2016;37(4):e59519.

40. Pandini A, D'Artibale EF, Paiano M, Marcon SS. Rede de apoio social e família: convivendo com um familiar usuário de drogas. Cienc Cuid Saude. 2016;15(4):716-22.

41. Minayo MCS. Análise qualitativa: teoria, passos e fidedignidade. Ciênc Saúde Coletiva. 2012;17(3):621-6.

42. Moules NJ, Venturato L, Laing CM, Field JC. Is it really "yesterday's war"? what Gadamer has to say about what gets counted. J Applied Hermeneutics. 2017; Article 1.

43. Sluzki CE. A rede social na prática sistêmica: alternativas terapêuticas. São Paulo: Casa do Psicólogo; 1997

44. Shimizu HE, Rosales C. As práticas desenvolvidas no Programa Saúde da Família contribuem para transformar o modelo de atenção à saúde? Rev Bras Enferm. 2009;62(3):424-9.

45. Krause N, Borawisk-Clarck E. Social class differences in social support among older adults. Gerontologist. 1995;35(4):498-508. 
46. França MS. Validação de instrumentos de medição das práticas apoiadoras da rede social à mulher/nutriz [dissertação]. Recife (PE): Universidade Federal de Pernambuco; 2015.

47. Silveira CL, Budó MDLD, Silva FM, Beuter M, Schimith MD. Rede social das cuidadoras de familiares com doença crônica incapacitante no domićlio: implicações para a enfermagem. Ciênc Cuid Saúde. 2009;8(4):667-74.

48. Sousa AM, Fracolli LA, Zoboli ELCP. Práticas familiares relacionadas à manutenção da amamentação: revisão da literatura e metassíntese. Rev Panam Salud Publica. 2013;34(2):127-34.
49. Dumitru RC, Bürkle T, Potapov T, Lausen B, Wiese B, Prokosch HU. Use and perception of Internet for health related purposes in Germany: results of a national survey. Int J Public Health. 2007;52(5):275-85.

50. Nobrega VM, Collet N, Silva KL, Coutinho SED. Rede e apoio social das famílias de crianças em condição crônica. Rev Eletr Enferm. 2010;12(3):431-40.

51. Charon JM. Symbolic interactionism: an introduction, an interpretation, an integration. 9th ed. Englewood Cliffs: Prentice Hall; 2007.
Autor correspondente:

Michelline Santos de França

E-mail: michellinedefranca@gmail.com
Recebido: 25.01.2018

Aprovado: 02.07.2018 